\title{
Association between type of exercise and health-related quality of life in adults without activity limitations: a nationwide cross-sectional study
}

Min-Jung Choi ${ }^{1}$, Yong Gyu Park ${ }^{2 *}$, Yang Hyun Kim ${ }^{3}$ Kyung Hwan Cho ${ }^{3}$ and Ga Eun $\mathrm{Nam}^{3^{*}}$

\begin{abstract}
Background: Exercise is known to be associated with health-related quality of life (HRQoL), however, evidence on the association between type of exercise and HRQoL in the general population is limited. We performed this study to investigate the association of exercise types and their combinations with HRQoL in Korean adults.

Methods: We analyzed data from 13,437 adults aged $\geq 19$ years without activity limitations who had participated in the 5th Korea National Health and Nutrition Examination Survey 2010-2012. As per the American College of Sports Medicine guideline, exercise types were categorized into eight groups: walking (W), flexibility (F), resistance (R), W + $F, W+R, F+R$, and $W+F+R$ exercise groups and a non-exercise group. The European Quality of Life-5 Dimension (EQ-5D) index and the European Quality of Life Visual Analogue Scale (EQ-VAS) were used to assess HRQoL.

Results: The mean age of participants was $42.8 \pm 0.2$ years. The proportion of participants in the non-exercise group was the highest (34.7\%); among the exercise groups, the walking group was the most prevalent (16.9\%) and the $W+R$ group was the least (1.2\%). In analysis of covariance, the mean EQ-5D index in $W(0.875), W+F(0.878), F+R$ $(0.877)$, and $W+F+R(0.876)$ groups was significantly higher compared with that in non-exerciser group (0.869) $(p<0.05)$. The mean EQ-VAS score in the $\mathrm{W}$ (64.064), $\mathrm{F}$ (64.427), $\mathrm{W}+\mathrm{F}$ (65.676), $\mathrm{F}+\mathrm{R}(65.811)$, and $\mathrm{W}+\mathrm{F}+\mathrm{R}(67.110)$ groups was higher than that in the non-exercise group (62.396) $(p<0.05)$. No difference was observed between $R$ and $W+R$ groups and non-exercise group with regard to the EQ-5D index and EQ-VAS score.

Conclusions: The $W$ (for 30 min at least five times a week), $W+F, F+R$ (at least two days a week), and $W+F+R$ groups showed higher HRQOL than the non-exercise group. This study may be helpful in the development of public exercise interventions, which could help enhance HRQoL in adults.
\end{abstract}

Keywords: Quality of life, EQ-5D, EQ-VAS, Walking, Flexibility exercises, Resistance training

* Correspondence: ygpark@catholic.ac.kr; namgaaa@daum.net

2Department of Biostatistics, College of Medicine, The Catholic University of Korea, Seoul, Republic of Korea

${ }^{3}$ Department of Family Medicine, Korea University Anam Hospital, Korea University College of Medicine, Seoul, Republic of Korea

Full list of author information is available at the end of the article

C The Author(s). 2020 Open Access This article is licensed under a Creative Commons Attribution 4.0 International License, which permits use, sharing, adaptation, distribution and reproduction in any medium or format, as long as you give appropriate credit to the original author(s) and the source, provide a link to the Creative Commons licence, and indicate if changes were made. The images or other third party material in this article are included in the article's Creative Commons licence, unless indicated otherwise in a credit line to the material. If material is not included in the article's Creative Commons licence and your intended use is not permitted by statutory regulation or exceeds the permitted use, you will need to obtain permission directly from the copyright holder. To view a copy of this licence, visit http://creativecommons.org/licenses/by/4.0/. The Creative Commons Public Domain Dedication waiver (http://creativecommons.org/publicdomain/zero/1.0/) applies to the data made available in this article, unless otherwise stated in a credit line to the data. 


\section{Background}

Regular physical activity (PA) is associated with a reduced risk of cardiovascular disease [1], diabetes [2], disability, depression, anxiety [3], and all-cause mortality [4]. Exercise is a subcategory of PA that is planned, structured, repetitive, and aims to improve or maintain one or more components of physical fitness [5]. The American College of Sports Medicine (ACSM) guidelines for PA categorize the exercise according to: types (including walking, flexibility, and resistance exercise), intensity (including vigorous to moderate exercise), frequency (day/week), and duration (minutes) [6]. Concerning types of exercise the ACSM recommends aerobic, flexibility, and resistance exercise [6]. Despite interventions to promote PA including exercise in the Korean general population, the Korea Centers for Disease Control and Prevention (KCDC) reported that walking exercise has decreased by $20.1 \%$ over the last decade, and aerobic and muscle strength exercise has reduced by $7.9 \%$ over the last three years [7].

Health-related quality of life (HRQoL) is defined as an individual's perceived physical and mental health over time $[8,9]$. As major health concerns have changed from communicable diseases to non-communicable diseases such as cardiovascular disease and cancer [10], interest in qualitative indicators such as HRQoL has increased. HRQoL is an important indicator for evaluating the effects of public health programs as well as monitoring mortality [11-13]. There are various tools to assess HRQoL. Among them, the European Quality of Life-5 Dimension (EQ-5D) questionnaire has been widely used to measure HRQoL in many population-based surveys because of its simplicity and brevity [14].

PA including exercise is associated with HRQoL [15-17]. Previous studies have examined the association between PA intensity-based on the International Physical Activity Questionnaire (IPAQ) [18] —and HRQoL. Cross-sectional studies with 5537 adults (40-60 years) in England [16], 2853 Korean elderly people [19], and 10,392 adults aged 40 years or over in Korea [20] have shown that higher levels of PA are associated with better HRQoL.; However, studies on the association between exercise type and HRQoL have been limited to patients with specific illnesses or older people [21, 22]. Previous studies have analyzed only three types of exercise-walking, flexibility, and resistance exercise-and have not considered the fact that individuals may perform two or more combined exercises. Moreover, exercise type is associated with a combination of individual characteristics such as age, sex, marital status, educational level, body mass index (BMI), disease, and circumstances such as infrastructure in the communities for PA [23]. There is limited evidence on the association between type of exercise and HRQoL considering various confounding factors including participants' sociodemographics, health behaviors, and health conditions in the general population.
The dearth of evidence is mainly because a comparison between seven exercise types (three types of exercise and combined exercises) and a non-exercise group requires a large sample and significant funding.

Therefore, to fill this gap in existing research, this study aimed to investigate the association between three types of exercise and combination exercises and HRQoL in adults, considering societal, environmental, and behavioral factors using nationwide data representative of the South Korean population.

\section{Methods}

\section{Survey overview and study population}

This population-based cross-sectional study used data obtained from the 5th Korea National Health and Nutrition Examination Survey (KNHANES V) performed between 2010 and 2012. The KNHANES is a cross-sectional and nationally representative survey to evaluate health and nutritional status and to calculate the health indices of the South Korean population. It has been conducted every year by the KCDC since 1998. This survey uses a stratified cluster sampling design for the selection of participants and consists of three parts: a health interview, a nutrition survey, and a health examination. The health interview of the KNHANES $\mathrm{V}$ was conducted at mobile examination centers, and the response rate was $80.0 \%$. The KNHANES data are publicly available, and any researcher can download the data from the following website: https://knhanes. cdc.go.kr/knhanes/eng/index.do.

The KNHANES V included 25,534 participants. Of these, 19,599 participants were aged 19 years or older. The 4727 individuals who did not respond to the questions regarding exercise, HRQoL, or socioeconomic status were excluded from the present analysis. Further, 1435 respondents who reported being restricted in activities of daily living (ADL) and social activities owing to health problems or physical/mental disabilities were also excluded. Finally, a total of 13,437 participants were included in this study (Fig. 1). The research ethics committees of the KCDC approved the survey protocol, and informed consent was provided by all participants. This study was approved by the institutional review board of the Catholic University of Korea, St. Mary's Hospital in Seoul (approval number: KC18ZESI0062).

\section{Assessment of type of exercise}

Participants responded to the questionnaires regarding type and frequency of exercise. Regarding walking exercise, it was assessed using the Korean version of the IPAQ [18]. Participants were asked the following questions: "how many days did you walk for at least $10 \mathrm{mi}$ nutes during the last 7 days?" and "how long did you walk per day on these days?" Regarding flexibility and resistance exercise, participants were asked the following: 


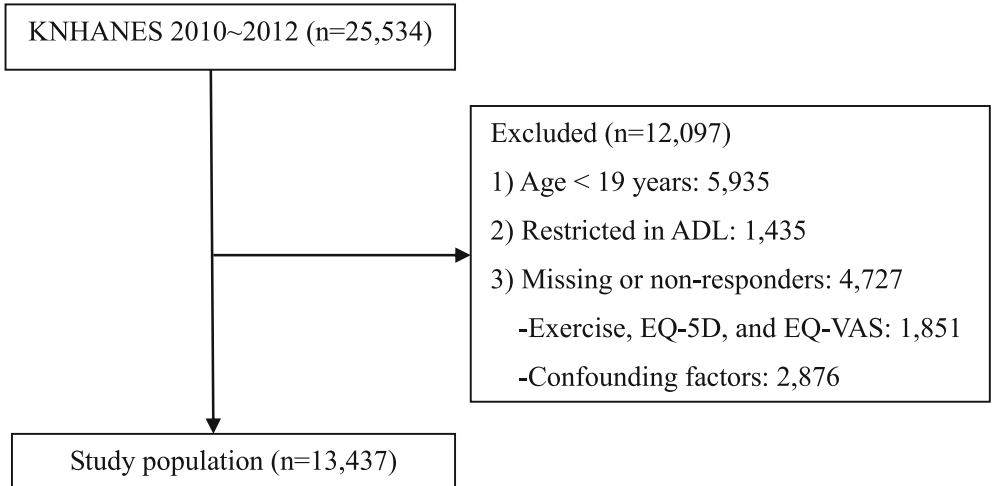

Fig. 1 Participant flow diagram illustrating the number of excluded individuals

"how many days did you perform flexibility exercise such as stretches or free gymnastics focused on flexibility during the last 7 days?" and "during the last 7 days, how many days did you perform resistance exercise such as push-ups, sit-ups, dumbbells, weights, and chin-ups?" According to the guidelines recommended by the ACSM, the walking exercise group was defined as individuals who walked more than $30 \mathrm{~min}$ a day for more than five days a week. The flexibility and resistance exercise groups were defined as individuals who performed flexibility and resistance exercise for more than two days a week, respectively [6]. Subsequently, participants were classified into eight groups: a non-exercise group who did not perform any exercise as recommended, three groups performing only one type of exercise (walking $[\mathrm{W}]$, flexibility $[\mathrm{F}]$, and resistance $[\mathrm{R}]$ exercise), three groups performing two types of exercise together (walking and flexibility $[\mathrm{W}+\mathrm{F}]$, walking and resistance $[\mathrm{W}+$ $R]$, and flexibility and resistance $[F+R]$ ), and one group performing all three types of exercise $(W+F+R)$.

\section{Assessment of HRQoL}

HRQoL was evaluated using the Korean version of the European Quality of Life (EuroQoL) Scale [14], which consists of two parts: the health-status descriptive system EQ-5D and the EuroQoL Visual Analogue Scale (EQ-VAS). The EQ-5D 3 level comprises five dimensions (mobility, self-care, usual activities, pain/discomfort, and anxiety/depression), and each dimension is assessed based on a single question with three response levels (no problem, some problems, and extreme problems). Participants indicate their current health (on the day of the questionnaire administration) by ticking one of the three response boxes for each of the five dimensions. Combining these answers constitutes 243 health states EQ-5D scores were calculated using the weighted model to transform these health states into Korean population-based health states [24]. Scores in the Korean EQ-5D index range from -1 to 1 , where $0 \leq \mathrm{a}$ health status worse than death, $0=$ death, and $1=$ perfect health status [25]. Respondents also indicated their current subjective health status using the EQ-VAS, which is designed on a vertical ruler from 0 (worst imaginable health state) to 100 (best imaginable health state), in increments of one. The Korean versions of the EQ-5D and EQ-VAS have been evaluated for their validity and reliability $[24,26]$.

\section{Covariates}

We considered age, sex, household income, education level, marital status, and area of residence as socio-demographic variables. Participants were divided according to age into: young-aged (19-39 years), middle-aged (40-64 years), and elderly (over 65 years) individuals. Household income was the total income of a household in the last year, including all income such as wages, real estate income, pensions, interest, and government subsidies. Household income was calculated as the equivalised income (= total household income per month $/ \sqrt{\text { number of family members }})$. The quartiles were divided into lowest, lower intermediate, higher intermediate, and highest groups according to the sample household income quartile threshold in the KNHANES. Education level was divided into four groups (elementary school or below, middle school, high school, and university or higher). Marital status was reported as unmarried, with spouse, and without spouse. Regarding area of residence, participants dwelling in a "dong" (neighborhood) were defined as urban dwellers, whereas those living in an "eup" (town) or "myeon" (township) were defined as rural dwellers.

BMI was calculated as the individual's body weight $(\mathrm{kg})$ divided by the square of height $(\mathrm{m})$, and then classified into three groups: underweight $\left(<18.5 \mathrm{~kg} / \mathrm{m}^{2}\right)$, normal to overweight $\left(18.5-24.9 \mathrm{~kg} / \mathrm{m}^{2}\right)$, and obese $(\geq 25$ $\mathrm{kg} / \mathrm{m}^{2}$ ) [27]. Participants were classified as never smokers, former smokers (had smoked $\geq 100$ cigarettes during their lifetime but were not smoking currently), and current smokers (had smoked $\geq 100$ cigarettes and 
were still smoking). Individuals with 8 points or higher on the Alcohol Use Disorder Identification Test (AUDIT) were considered problem drinkers [28]. ADL level was divided into three groups (light, normal, and severe activity). Participants were also asked whether they had ever been diagnosed by a physician with hypertension, diabetes, stroke, heart diseases (myocardial infarction or angina), arthritis (osteoarthritis or rheumatoid arthritis), or any malignancy.

\section{Statistical analysis}

The SAS survey procedure (version 9.3, SAS Institute, Cary, NC, USA) was used to account for the complex sampling design. The KNHANES $\mathrm{V}$ is based on a twostage stratified cluster sampling method with districts and households, and the sampling weights were obtained from these strata. Data were presented as mean \pm standard error (SE) for continuous variables or as percentage (SE) for categorical variables. Participants' characteristics according to type of exercise group were compared using one-way analyses of variance for continuous variables and Pearson chi-squared test for categorical variables. We compared the HRQoL indices (EQ-5D index and EQ-VAS) among eight exercise groups and calculated the significance of the difference using the analysis of covariance (ANCOVA) after adjustment for covariates. We then analyzed whether types of exercise are statistically different each other using Tukey's test for post hoc analysis. Model 1 was adjusted for age and sex, whereas model 2 was adjusted for age, sex, household income, education level, marital status, and area of residence. Model 3 was additionally adjusted for BMI, smoking status, alcohol consumption, ADL, and past medical history based on previous studies [29, 30]. Associations between type of exercise and HRQoL indices according to age and sex were examined using an ANCOVA after adjusting for all potential confounding variables (age, sex, household income, education level, marital status, area of residence, BMI, smoking status, alcohol consumption, ADL, and past medical history). Statistical significance was defined by a two-tailed $p$ value $<0.05$.

\section{Results}

\section{Characteristics according to type of exercise}

Participants' socio-demographic and clinical characteristics according to exercise type groups are shown in Tables 1 and 2. The demographic, economic, and lifestyle characteristics were significantly different among the exercise groups $(p<0.001)$. Their mean age was $42.8 \pm 0.2$ years, with the highest among those in the $\mathrm{F}+$ $\mathrm{R}$ group ( $44.8 \pm 0.5$ years). The proportion of males was the highest in the $\mathrm{W}+\mathrm{R}$ group (89.1\%). Income and educational levels were significantly different among exercise groups $(p<0.001)$ : the $\mathrm{W}$ group showed the highest rate of the lowest income level (lowest quartile group) and non-exerciser group showed the highest rate of the lowest educational level (selementary school). The proportion of urban dwellers was the highest in the $\mathrm{W}+\mathrm{F}$ group. The proportions of unmarried respondents, current smokers, and problem drinkers were high among individuals in the $\mathrm{R}$ and $\mathrm{W}+\mathrm{R}$ groups. The rate of underweight and obese individuals was the highest in the non-exercise group (6.3\%) and the $\mathrm{W}+\mathrm{R}$ group $(38.2 \%)$, respectively. The prevalence of hypertension $(p=0.015)$ and arthritis $(p<0.001)$ significantly differed among the exercise groups.

\section{Analysis of covariance regarding associations between type of exercise and HRQoL}

Table 3 presents the results from the analysis of covariance between type of exercise and HRQoL indices. The EQ-5D index and EQ-VAS scores were different among the eight groups after adjusting for confounding variables $(p<0.001)$. In model 1 , the $\mathrm{W}+\mathrm{F}, \mathrm{F}+\mathrm{R}$, and $\mathrm{W}+\mathrm{F}+\mathrm{R}$ groups exhibited higher scores of the EQ-5D index compared with the non-exercise group $(p<0.05)$. EQ-VAS scores in the $\mathrm{F}, \mathrm{W}+\mathrm{F}, \mathrm{W}+\mathrm{F}, \mathrm{W}+\mathrm{F}+\mathrm{R}$ groups were significantly higher than the non-exercise group $(p<0.05)$. These associations persisted after further adjustment for confounding variables in models 2 and 3 . In model 3, EQ$5 \mathrm{D}$ index in $\mathrm{W}(0.875 \pm 0.013), \mathrm{W}+\mathrm{F}(0.878 \pm 0.013), \mathrm{F}+$ $R(0.877 \pm 0.013)$, and $W+F+R(0.876 \pm 0.013)$ groups was significantly higher than that in the non-exercise group $(0.869 \pm 0.013)(p<0.05)$. EQ-VAS score in W $(64.064 \pm 1.549), \quad F \quad(64.427 \pm 1.530), \quad W+F \quad(65.676 \pm$ 1.491), F+R (65.811 \pm 1.565$)$, and $W+F+R(67.110 \pm$ $1.585)$ groups was also significantly higher than that in the non-exercise group $(62.396 \pm 1.530)(p<0.05)$.

\section{Adjusted means of HRQoL indices according to sex, age, and type of exercise}

Figures 2 and 3 show the adjusted means of the EQ-5D index and EQ-VAS score according to subgroups based on sex, age, and type of exercise after adjusting for all confounding variables. Both indices were higher in men than in women in all exercise type groups (Fig. 2). As for age, the mean of EQ-5D index was the highest in the middle-aged group (40-64 years), followed by the younger (19-39 years) and older ( $\geq 65$ years) age groups (Fig. 3). Regarding EQ-VAS score, a similar pattern was shown in the non-exerciser, $\mathrm{F}$, and $\mathrm{F}+\mathrm{R}$ groups.

\section{Discussion}

This study examined the association between type of exercise and HRQoL using a nationally representative data of South Korean adults. Compared with the nonexercise group, the EQ-5D index was significantly higher 


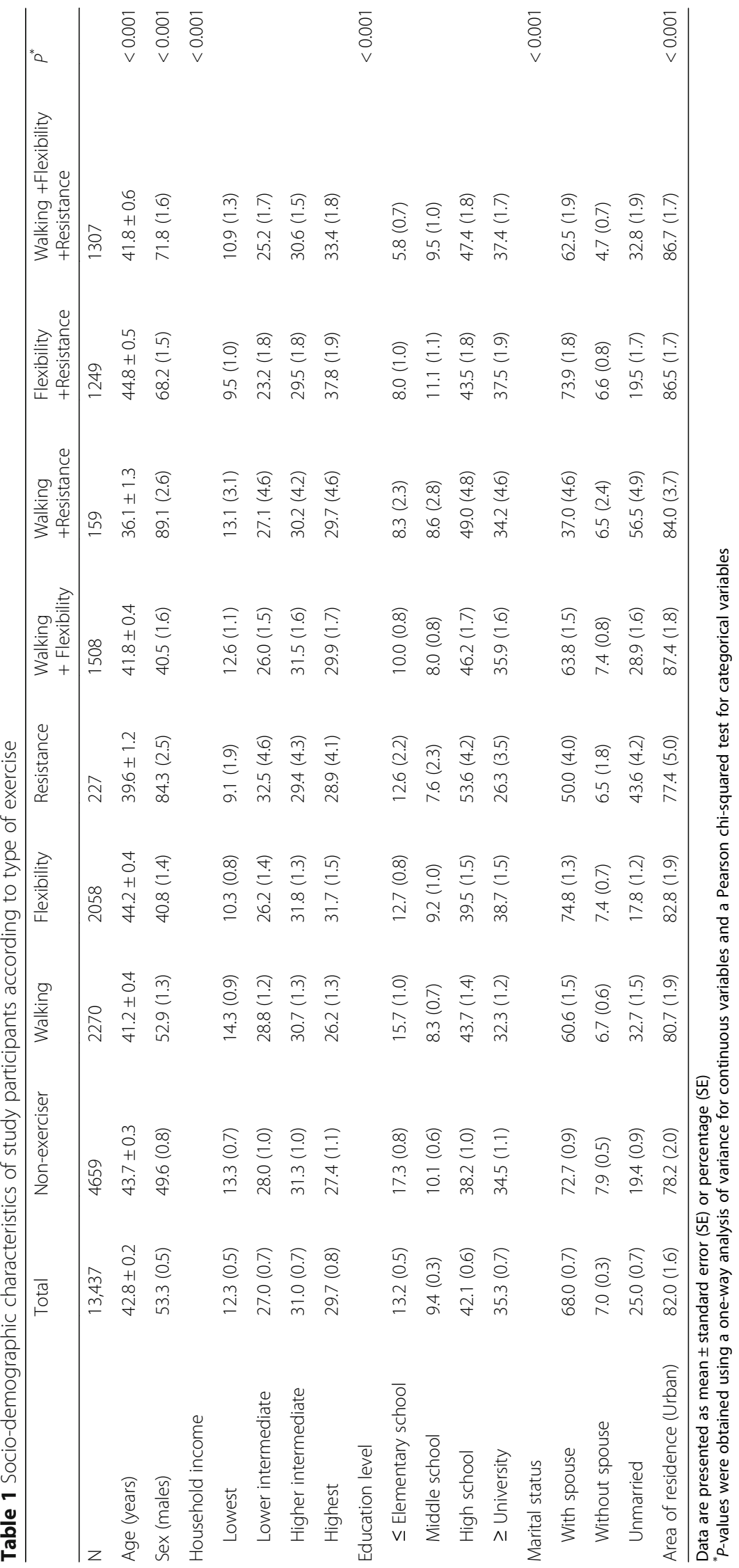




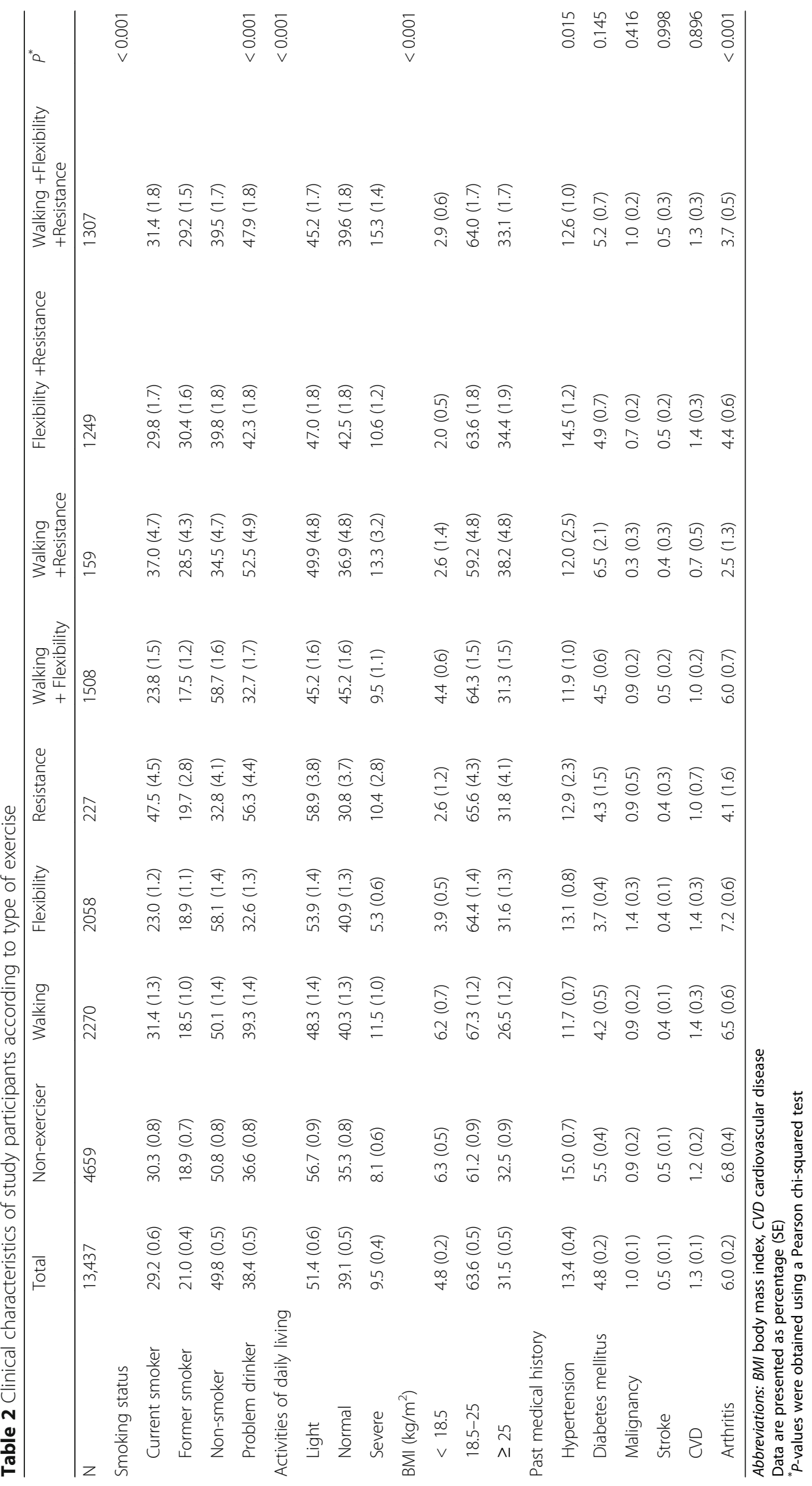


Table 3 Analysis of covariance of HRQoL indices according to type of exercise

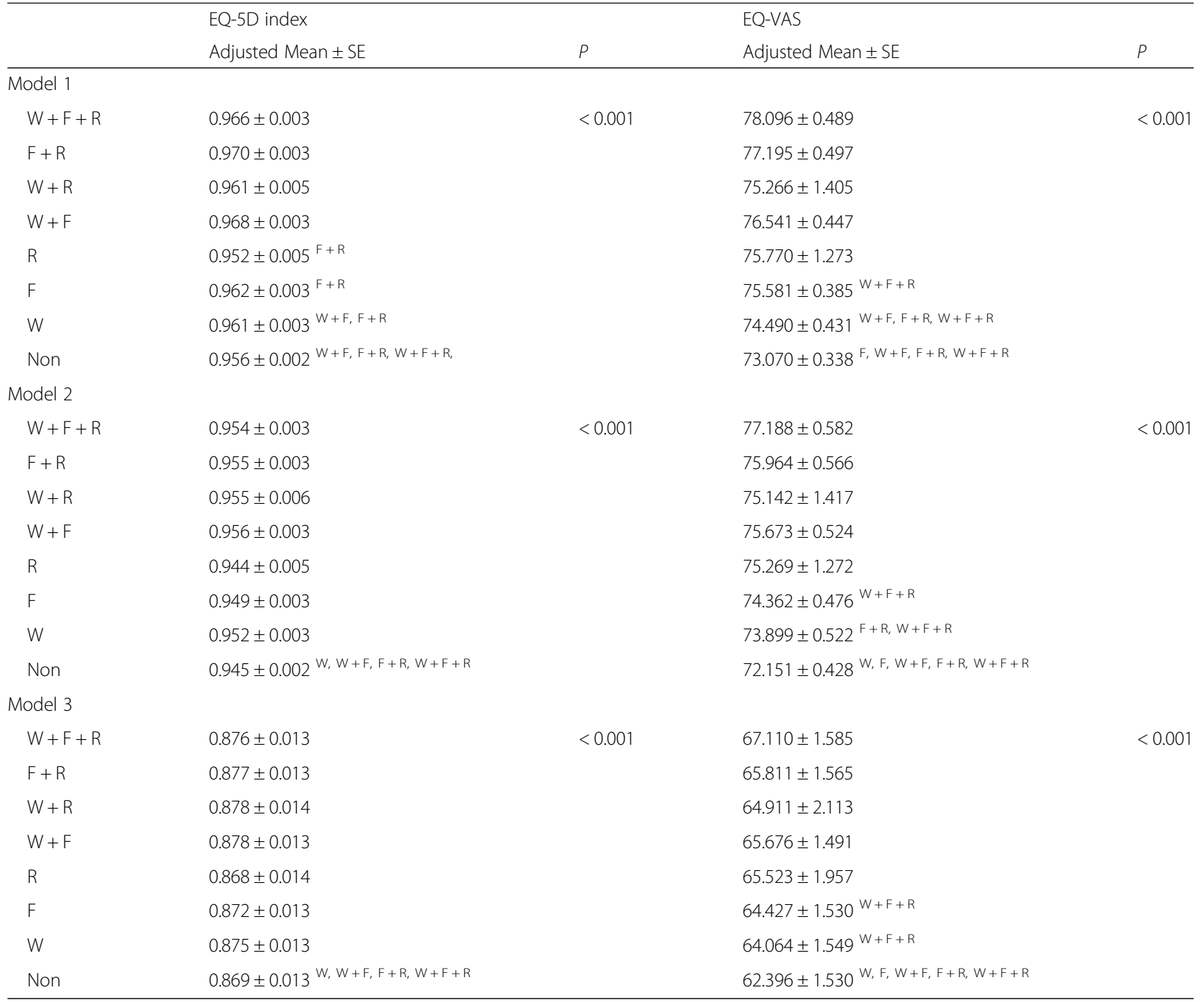

Abbreviations: $H R Q o L$ health-related quality of life, EQ-5D EuroQol 5-dimension, EQ-VAS EuroQol visual analogue scale, Non non-exerciser, $W$ walking, $F$ flexibility, $R$ resistance, SE standard error,

$P$-values were obtained by ANCOVA

Superscripts indicate statistically different groups $(p<0.05)$ with the corresponding type of exercise by Tukey's test for post hoc analysis

Model 1 was adjusted for age and sex

Model 2 was adjusted for model 1 plus household income, education level, marital status, and area of residence

Model 3 was adjusted for model 2 plus smoking status, alcohol drinking, activity of daily living, body mass index, and past medical history

in the $\mathrm{W}, \mathrm{W}+\mathrm{F}, \mathrm{F}+\mathrm{R}$, and $\mathrm{W}+\mathrm{F}+\mathrm{R}$ exercise groups, and the EQ-VAS score was higher in the $W, F, W+F$, $\mathrm{F}+\mathrm{R}$, and $\mathrm{W}+\mathrm{F}+\mathrm{R}$ exercise groups. These findings indicate that walking exercise and combinations of two or three types of exercise as recommended may positively affect HRQoL.

Previous studies on HRQoL have identified age, sex, education, income, BMI, stress, and the number of chronic diseases as factors affecting EQ-5D index [29, $31,32]$. The present study considered these confounding variables in the analysis of the association between types of exercise and HRQoL. With respect to these variables, we found that the proportion of participants performing the recommended exercises was lower among individuals with lower socioeconomic status, without a spouse, with a rural residence, with low BMI (underweight), women, and older ages (Table 1).

A key question in this study was whether type of exercise is associated with HRQoL compared to individuals who do not exercise. Based on the results using two HRQoL assessment tools, walking and combined exercise types showed significant positive associations with HRQoL indices. Walking is positively correlated with the EQ-5D index, which is consistent with findings from a previous questionnaire survey of 351 healthy adults [33] and another study that showed increased HRQoL in 

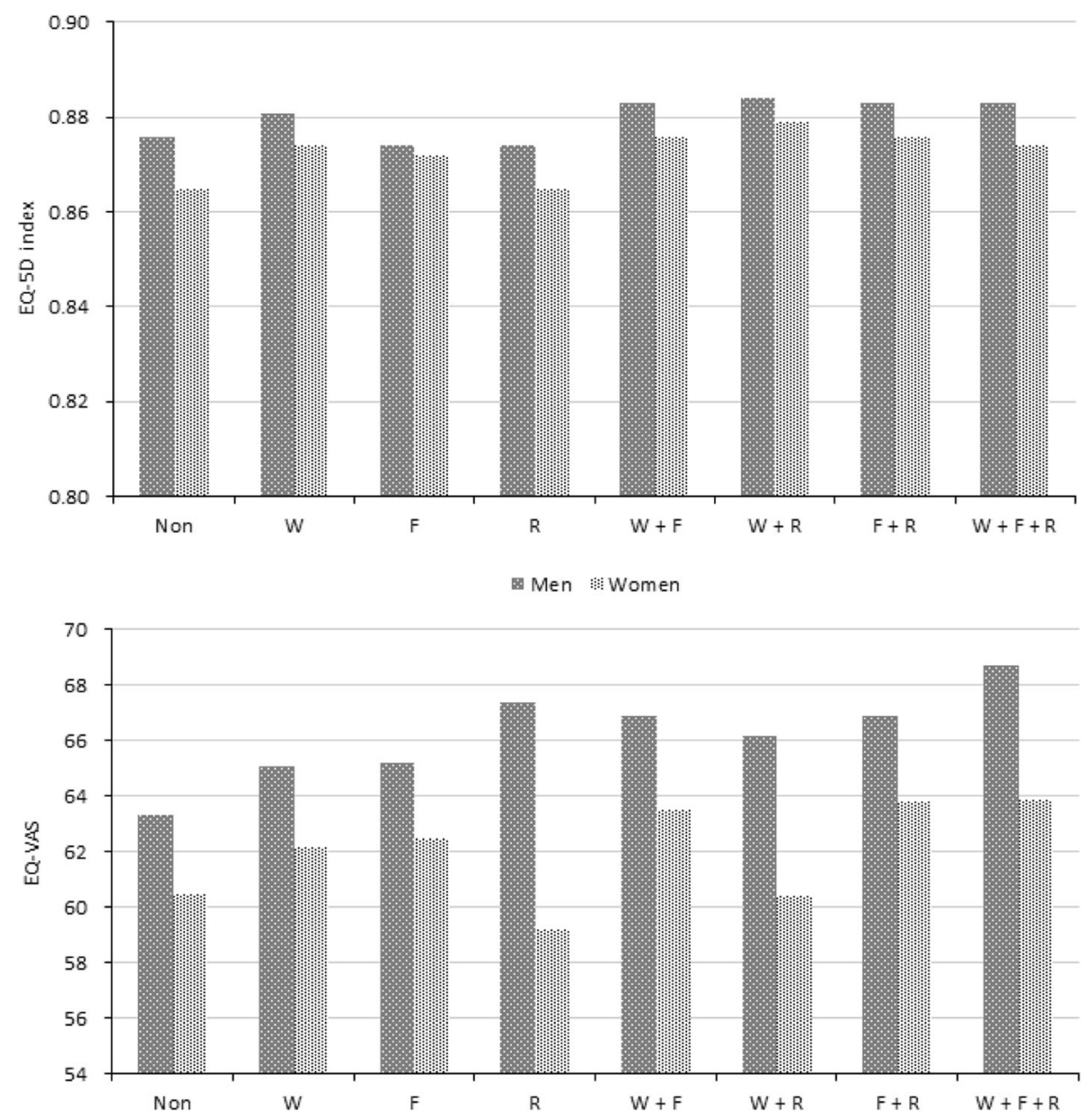

Fig. 2 Adjusted means of EQ-5D index and EQ-VAS score according to sex and type of exercise

adults after walking exercise for 12 weeks [34]. Further, a combination of aerobic and flexibility exercise such as Tai chi and Qigong [35] and resistance and flexibility exercise [36] improved HRQoL, which is similar to our findings. The EQ-VAS score was higher in the $\mathrm{W}+\mathrm{F}+\mathrm{R}$ group than the non-exercise, $\mathrm{W}$, and $\mathrm{F}$ groups. This finding is consistent with a previous study in which the HRQoL of participants who performed three combined exercise types was improved [37]. These results indicate that it may be necessary to consider combined exercise types in the development of public exercise interventions to improve HRQoL.

We found no differences in the EQ-5D index between groups that performed only flexibility or resistance exercise and the non-exercise group. A study for adults with metabolic syndrome reported that the EQ-5D index is not associated with flexibility or resistance exercise [22]. In elderly persons aged over 65 years, flexibility exercise was related to mobility and self-care, whereas resistance exercise was related only to mobility [21]. Thus, the association of flexibility and resistance exercise with
HRQoL may be attributable to the characteristics of participants. Our results show that performing only flexibility or resistance exercise may not be sufficient for having a positive effect on the EQ-5D sub-dimensions. In addition, individuals performing only flexibility or resistance exercise may be doing so owing to limited flexibility or muscularity; in other words, they may not be in a state to perform other types of exercise, such as walking, or combined types of exercise.

Although the $\mathrm{W}+\mathrm{R}$ group and the non-exercise group showed no significant difference in the EQ-5D index and EQ-VAS scores, HRQoL has been reported to improve with the performance of the $\mathrm{W}+\mathrm{R}$ exercise in the general population as well as in those with heart failure and diabetes [38-41]. In the present study, a small number of participants performed only resistance exercise, and the sample of the $\mathrm{W}+\mathrm{R}$ group was the smallest. Further research with larger samples is needed to reveal the association between performing $\mathrm{W}+\mathrm{R}$ exercise and HRQoL. Moreover, as the number of participants who performed resistance exercise was too small, it is 

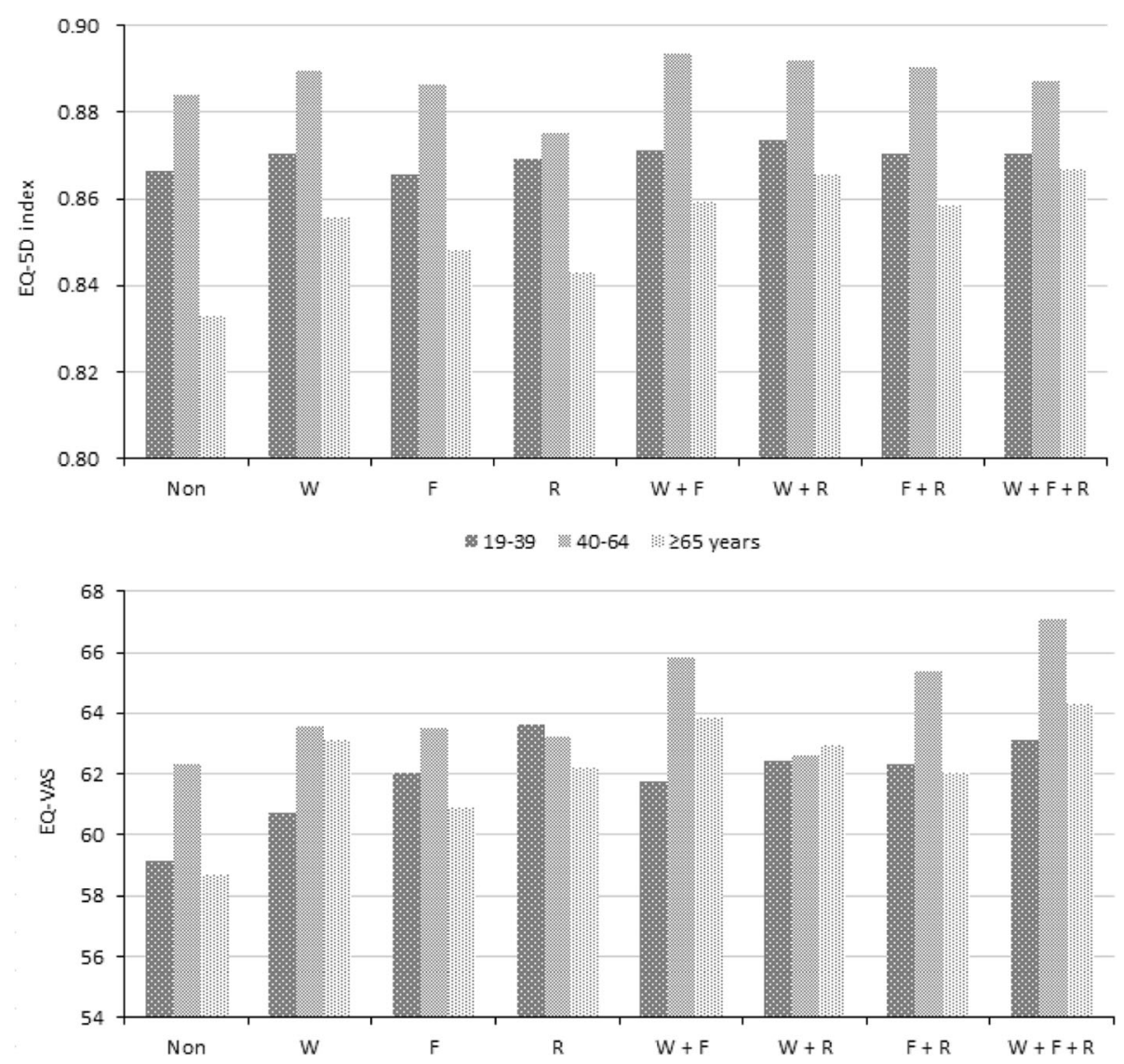

Fig. 3 Adjusted means of EQ-5D index and EQ-VAS score according to age and type of exercise

necessary to emphasize resistance exercise along with other types of exercise in public exercise interventions.

The EQ-VAS score was higher in the group that performed walking and flexibility exercise compared with the non-exercise group. This finding can be attributed to differences in the scoring mechanisms of the EQ-5D index and EQ-VAS. The EQ-5D index reflects general health status and includes a wide range of health problems by sub-dimension. The EQ-VAS, meanwhile, measures respondents' health status on the day they complete the questionnaire and may not necessarily be associated with their current health status [42]. Internal factors, such as the satisfaction of performing any exercise regularly, are highly likely to affect the EQ-VAS score.

Given the overall design of this study, there are several limitations. First, there may be potential recall bias because the type of exercise and other lifestyle factors were based on information collected retrospectively using self-reported questionnaires. Second, we cannot confirm a causal association between type of exercise and HRQoL due to the cross-sectional design of our study. Third, this study did not measure the intensity of each exercise type that could influence HRQoL and this should be addressed in further studies. Fourth, there might be other activities (e.g. cycling) that participants could be involved and were not gathered in the established groups and might have influenced the participants' HRQoL. Fifth, individuals with limitations of ADL or social activity due to health problems and physical or mental disabilities were excluded from the current analysis; therefore, it is necessary to conduct further studies by considering such individuals. Sixth, because this study was based on the nationwide data of South Korea, it cannot be generalized to other populations.

\section{Conclusions}

This study showed that different types of exercise are differently associated with HRQoL in Korean adults. Walking and a combination of two or three types of exercises were positively associated with HRQoL. Our results may be helpful in the development of public exercise interventions to improve HRQoL in adults. Future research should examine the association of the combination of walking and resistance exercise with HRQoL. Moreover, it will be meaningful to consider a specific population, such as noncommunicable diseases, in this regard. Further studies should be to perform a longitudinal study rather than cross-sectional, to observe long- term changes. 


\section{Abbreviations}

HRQoL: Health-related quality of life; KNHANES: Korea National Health and Nutrition Examination Survey; W: Walking; F: Flexibility; R: Resistance; EQ5D: European Quality of Life-5 Dimension; EQ-VAS: European Quality of Life Visual Analogue Scale; ACSM: American College of Sports Medicine; KCDC: Korea Centers for Disease Control and Prevention; IPAQ: International Physical Activity Questionnaire; ADL: Activities of daily living; EuroQoL: European Quality of Life; BMI: Body mass index; AUDIT: Alcohol Use Disorder Identification Test; ANOVA: Analysis of Covariance; SE: Standard error; Non: Non-exerciser

\section{Acknowledgements}

The authors would like to thank the Korea Centers for Disease Control and Prevention for providing the data.

\section{Authors' contributions}

MJC, YGP, and GEN were the principal investigators. They contributed substantially to the study design, literature search, collection and assembly of data, data analyses, and data interpretation. They wrote all drafts and revised the manuscript. YHK and KHC contributed to the data interpretation and critical revision of the manuscript. YGP and GEN had full access to all the data in the study and took responsibility for the integrity of the data and the accuracy of the data analysis. All authors approved the final version of the manuscript and had responsibility for the decision to submit for publication.

\section{Funding}

No funding was obtained for this study.

\section{Availability of data and materials}

Survey data supporting the conclusions of this article are publicly available at https://knhanes.cdc.go.kr/knhanes/main.do through the submission of a written plan for data utilization.

\section{Ethics approval and consent to participate}

This study was approved by the institutional review board of the Catholic University of Korea, St. Mary's Hospital in Seoul (approval number: KC18ZESI0062). The research ethics committees of the Korea Centers for Disease Control and Prevention (KCDC) approved the survey protocol, and written consent was provided by all participants. The KNHANES data are deidentified and publicly available.

\section{Consent for publication}

Not applicable.

\section{Competing interests}

The authors declare that they have no competing interests.

\section{Author details}

'Department of Nursing, College of Nursing, The Catholic University of Korea, Seoul, Republic of Korea. ${ }^{2}$ Department of Biostatistics, College of Medicine, The Catholic University of Korea, Seoul, Republic of Korea. ${ }^{3}$ Department of Family Medicine, Korea University Anam Hospital, Korea University College of Medicine, Seoul, Republic of Korea.

Received: 20 December 2018 Accepted: 14 April 2020 Published online: 01 May 2020

\section{References}

1. Echouffo-Tcheugui JB, Butler J, Yancy CW, Fonarow GC. Association of Physical Activity or fitness with incident heart failure: a systematic review and meta-analysis. Circ Heart Fail. 2015;8(5):853-61. https://doi.org/10.1161/ circheartfailure.115.002070.

2. Pai LW, Li TC, Hwu YJ, Chang SC, Chen LL, Chang PY. The effectiveness of regular leisure-time physical activities on long-term glycemic control in people with type 2 diabetes: a systematic review and meta-analysis. Diabetes Res Clin Pract. 2016;113:77-85. https://doi.org/10.1016/j.diabres. 2016.01.011.

3. Rosenbaum S, Tiedemann A, Sherrington C, Curtis J, Ward PB. Physical activity interventions for people with mental illness: a systematic review and meta-analysis. J Clin Psychiatry. 2014;75(9):964-74. https://doi.org/10.4088/ JCP.13r08765.
4. Kelly P, Kahlmeier S, Götschi T, Orsini N, Richards J, Roberts N, et al. Systematic review and meta-analysis of reduction in all-cause mortality from walking and cycling and shape of dose response relationship. Int J Behav Nutr Phys Act. 2014;11:132. https://doi.org/10.1186/s12966-014-0132-x.

5. Caspersen CJ, Powell KE, Christenson GM. Physical activity, exercise, and physical fitness: definitions and distinctions for health-related research. Public Health Rep (Washington, DC : 1974). 1985;100(2):126-31 published Online First: 1985/03/01.

6. American College of Sports Medicine. ACSM's guidelines for exercise testing and prescription. 10th ed. Philadelphia: Wolters Kluwer Health; 2018.

7. Korea Centers for Disease Control and Prevention. Major findings in 2016 Korean national health and nutrition examination survey (KNHANES VII) 2017. http://www.moe.go.kr/boardCnts/view.do?boardID=294\&boardSeq= 72430\&lev $=0 \&$ searchType $=$ null\&status $Y N=C \&$ page $=1 \& s=$ moe $\& m=0503$ \&opType $=$ N. Accessed 1 March 2018.

8. Hennessy CH, Moriarty DG, Zack MM, Scherr PA, Brackbill R. Measuring health-related quality of life for public health surveillance. Public Health Rep. 1994;109(5):665-72.

9. Centers for Disease Control and Prevention. Measuring Healthy Days: Population assessment of health-related quality of life. Atlanta: CDC; 2000. p. 5-7.

10. GBD 2015 Risk Factors Collaborators. Global, regional, and national comparative risk assessment of 79 behavioural, environmental and occupational, and metabolic risks or clusters of risks, 1990-2015: a systematic analysis for the Global Burden of Disease Study 2015. Lancet. 2016;388(10053):1659-724. https://doi.org/10.1016/s0140-6736(16)31679-8.

11. Scocco P, Fantoni G, Caon F. Role of depressive and cognitive status in selfreported evaluation of quality of life in older people: comparing proxy and physician perspectives. Age Ageing. 2006:35(2):166-71. https://doi.org/10. 1093/ageing/afj026.

12. Fernández-Ruiz M, Guerra-Vales JM, Trincado R, Fernández R, Medrano MJ, Villarejo A, et al. The ability of self-rated health to predict mortality among community-dwelling elderly individuals differs according to the specific cause of death: data from the NEDICES cohort. Gerontology. 2013;59(4):36877. https://doi.org/10.1159/000348781.

13. Mapes DL, Lopes AA, Satayathum S, McCullough KP, Goodkin DA, Locatelli $F$, et al. Health-related quality of life as a predictor of mortality and hospitalization: the Dialysis outcomes and practice patterns study (DOPPS). Kidney Int 2003;64(1):339-349, doi:https://doi.org/https://doi.org/10.1046/j. 1523-1755.2003.00072.x.

14. The EuroQol Group. EuroQol-a new facility for the measurement of healthrelated quality of life. Health Policy. 1990;16(3):199-208.

15. Fitzgerald B. Review: regular exercise improves quality of life and physical fitness in women with breast cancer. Evid Based Nurs. 2007;10(1):12. https:// doi.org/10.1136/ebn.10.1.12.

16. Anokye NK, Trueman P, Green C, Pavey TG, Taylor RS. Physical activity and health related quality of life. BMC Public Health. 2012;12:624. https://doi.org/ 10.1186/1471-2458-12-624.

17. Bize R, Johnson JA, Plotnikoff RC. Physical activity level and health-related quality of life in the general adult population: a systematic review. Prev Med. 2007;45(6):401-15. https://doi.org/10.1016/j.ypmed.2007.07.017.

18. Craig $C L$, Marshall AL, Sjostrom M, et al. International physical activity questionnaire: 12-country reliability and validity. Med Sci Sports Exerc. 2003; 35(8):1381-95. https://doi.org/10.1249/01.Mss.0000078924.61453.Fb.

19. Cho KO. The Positive Effect of Physical Activity on Health and Health-related Quality of Life in Elderly Korean People-Evidence from the Fifth Korea National Health and Nutrition Examination Survey. J Lifestyle Med. 2014;4(2): 86-94. https://doi.org/10.15280/jlm.2014.4.2.86 published Online First: 2015/ $06 / 13$.

20. Kim S, Kwon YM, Park YI. Association between physical activity and healthrelated quality of life in Korean: the Korea National Health and nutrition examination survey IV. Korean J Fam Med. 2014;35(3):152-9. https://doi.org/ 10.4082/kjfm.2014.35.3.152.

21. Oh SH, Kim DK, Lee SU, Jung SH, Lee SY. Association between exercise type and quality of life in a community-dwelling older people: a cross-sectional study. PLoS One. 2017;12(12):e0188335. https://doi.org/10.1371/journal.pone. 0188335.

22. Oh SH, Son SH, Kang SH, Kim DK, Seo KM, Lee SY. Relationship between types of exercise and quality of life in a Korean metabolic syndrome population: a cross-sectional study. Metab Syndr Relat Disord. 2017;15(4): 199-205. https://doi.org/10.1089/met.2016.0151. 
23. Herazo-Beltran Y, Pinillos Y, Vidarte J, Crissien E, Suarez D, Garcia R. Predictors of perceived barriers to physical activity in the general adult population: a cross-sectional study. Braz J Phys Ther. 2017;21(1):44-50. https://doi.org/10.1016/j.bjpt.2016.04.003.

24. Nam HS, Kim KY, Kweon SS, Koh KW, Kind P. Estimation report on quality weights for EQ-5D. Cheongju: Korea Centers for Disease Control and Prevention; 2007.

25. Lee YK, Nam HS, Chuang LH, Kim KY, Yang HK, Kwon IS, et al. South Korean time trade-off values for EQ-5D health states: modeling with observed values for 101 health states. Value Health. 2009;12(8):1187-93. https://doi. org/10.1111/j.1524-4733.2009.00579.x.

26. Korea Centers for Disease Control and Prevention. Validity and reliability evaluation for EQ-5D in Korea. 2011. http://koix.kisti.re.kr/root_resolution. jsp?koi=KISTI2.1015/RPT.TRKO201300000474. Accessed September 1, 2019.

27. Pan WH, Yeh WT. How to define obesity? Evidence-based multiple action points for public awareness, screening, and treatment: an extension of Asian-Pacific recommendations. Asia Pac J Clin Nutr. 2008;17(3):370-4.

28. Babor TF, Higgins-Biddle JC, Saunders JB, Monteiro MG, AUDIT: the alcohol use disorders identification test: guidelines for use in primary healthcare. 2nd ed. Geneva: World Health Organization; 2001. p.19-20.

29. Lubetkin El, Jia H, Franks P, Gold MR. Relationship among sociodemographic factors, clinical conditions, and health-related quality of life: examining the EQ-5D in the U.S. general population. Qual Life Res. 2005;14(10):2187-96. https://doi.org/10.1007/s11136-005-8028-5.

30. Baek MK, Kim YS, Kim EY, et al. Health-related quality of life in Korean adults with hearing impairment: the Korea National Health and nutrition examination survey 2010 to 2012. PLoS One. 2016;11(10):e0163999. https:// doi.org/10.1371/journal.pone.0163999.

31. Soltoft F, Hammer M, Kragh N. The association of body mass index and health-related quality of life in the general population: data from the 2003 health survey of England. Qual Life Res. 2009;18(10):1293-9. https://doi.org/ 10.1007/s11136-009-9541-8

32. Saarni SI, Härkänen $T$, Sintonen $H$, Suvisaari J, Koskinen S, Aromaa A, et al. The impact of 29 chronic conditions on health-related quality of life: a general population survey in Finland using 15D and EQ-5D. Qual Life Res. 2006:15(8):1403-14. https://doi.org/10.1007/s11136-006-0020-1.

33. Blacklock RE, Rhodes RE, Brown SG. Relationship between regular walking, physical activity, and health-related quality of life. J Phys Act Health. 2007; 4(2):138-52. https://doi.org/10.1123/jpah.4.2.138.

34. Gordon CD, Wilks R, McCaw-Binns A. Effect of aerobic exercise (walking) training on functional status and health-related quality of life in chronic stroke survivors: a randomized controlled trial. Stroke. 2013;44(4):1179-81. https://doi.org/10.1161/strokeaha.111.000642.

35. Liu X, Miller YD, Burton NW, et al. A preliminary study of the effects of Tai Chi and Qigong medical exercise on indicators of metabolic syndrome, glycaemic control, health-related quality of life, and psychological health in adults with elevated blood glucose. British J Sports Med. 2010;44(10):704-9. https://doi.org/10.1136/bjsm.2008.051144 published Online First: 2008/10/18.

36. Pourtaghi F, Emami Moghadam Z, Ramezani M, et al. Effect of Resistance Training using Thera-Band on Muscular Strength and Quality of Life among the Elderly. Evid Based Care. 2017;7(3):7-16. https://doi.org/10.22038/ebcj. 2017.25876.1584.

37. Sangelaji B, Nabavi SM, Estebsari F, Banshi MR, Rashidian H, Jamshidi E, et al. Effect of combination exercise therapy on walking distance, postural balance, fatigue and quality of life in multiple sclerosis patients: a clinical trial study. Iran Red Crescent Med J. 2014;16(6):e17173. https://doi.org/10. 5812/ircmj.17173.

38. Atlantis E, Chow CM, Kirby A, Singh MF. An effective exercise-based intervention for improving mental health and quality of life measures: a randomized controlled trial. Prev Med. 2004;39(2):424-34. https://doi.org/10. 1016/j.ypmed.2004.02.007.

39. Tomas-Carus P, Ortega-Alonso A, Pietilainen KH, Santos V, Goncalves H, Ramos J, et al. A randomized controlled trial on the effects of combined aerobic-resistance exercise on muscle strength and fatigue, glycemic control and health-related quality of life of type 2 diabetes patients. J Sports Med Phys Finess. 2016;56(5):572-8.

40. Oka RK, De Marco T, Haskell WL, Botvinick E, Dae MW, Bolen K, et al. Impact of a home-based walking and resistance training program on quality of life in patients with heart failure. Am J Cardiol. 2000;85(3):365-9. https://doi.org/ 10.1016/s0002-9149(99)00748-1.
41. Gomes Neto M, Conceição CS, Oliveira Carvalho V, Brites C. Effects of combined aerobic and resistance exercise on exercise capacity, muscle strength and quality of life in HIV-infected patients: a systematic review and meta-analysis. PLoS One. 2015;10(9):e0138066. https://doi.org/10.1371/ journal.pone.0138066.

42. Feng Y, Parkin D, Devlin NJ. Assessing the performance of the EQ-VAS in the NHS PROMs programme. Qual Life Res. 2014;23(3):977-89. https://doi. org/10.1007/s11136-013-0537-z.

\section{Publisher's Note}

Springer Nature remains neutral with regard to jurisdictional claims in published maps and institutional affiliations.

\section{Ready to submit your research? Choose BMC and benefit from:}

- fast, convenient online submission

- thorough peer review by experienced researchers in your field

- rapid publication on acceptance

- support for research data, including large and complex data types

- gold Open Access which fosters wider collaboration and increased citations

- maximum visibility for your research: over $100 \mathrm{M}$ website views per year

At BMC, research is always in progress.

Learn more biomedcentral.com/submissions 